\title{
A representação social de si mesmo e da profissão docente de professores de Educação Física da Educação Básica
}

\author{
Hugo Norberto Krug ${ }^{1}$ \\ Marilia de Rosso $\mathrm{Krug}^{2}$ \\ Rodrigo de Rosso $\mathrm{Krug}^{3}$ \\ Cassiano Telles ${ }^{4}$ \\ Patric Paludett Flores ${ }^{5}$
}

\begin{abstract}
Resumo
O objetivo deste estudo foi analisar as Representaçóes Sociais (RS) de si mesmo e da profissão docente e suas justificativas de professores de Educação Física (EF) da Educação Básica (EB) de uma cidade da região central do Rio Grande do Sul. Esta pesquisa qualitativa descritiva do tipo estudo de caso utilizou como instrumento o Teste de Associação Livre de Palavras, tendo a interpretação por meio da análise de conteúdo. Participaram 20 professores de EF da EB da referida cidade. Concluímos que foi possível representar a profissão docente em duas palavras (trabalho e sustento), o trabalho docente em cinco palavras (ensinar, gratificante, desvalorização, estressante e isolado) e ser professor também em cinco palavras (educador, vocação, profissional, conhecimento e amigo), sendo que das doze palavras, nove foram com conotação positiva e três com conotação negativa. Assim, as RS dos professores estudados sobre a temática são positivas em sua maioria.
\end{abstract}

Palavras-chave: Educação Física. Representação Social. Profissão Docente. Educação Básica.

\begin{abstract}
The objective of this study was to analyze the Social Representations (SR) of yourself and of teaching profession and their justifications of Physical Education (PE) teachers of Basic Education (BE) of a city in the central region of the Rio Grande do Sul. This descriptive qualitative research of study of the case type used as instrument the Free Word Association Test, have the interpretation through content analysis. Participatd twenty PE teachers of $\mathrm{BE}$ of that city. We concluded that it was possible to represent the teaching profession in two words (work and suport), the teaching work in five words (teaching, gratifying, devaluating, stressful and isolated) and being teacher also in five words (educator, vocation, professional, friend), being that of the twelve words, nine were with positive connotation and three with negative connotation. Thus, the SR of PE theachers of BE studied about the teaching profession, the teaching work and being teacher are mostly positive.
\end{abstract}

Keywords: Physical Education. Social Representation. Teaching Professional. Basic Education.

\footnotetext{
${ }^{1}$ Doutor em Educaçáo (UNICAMP/UFSM); Doutor em Ciência do Movimento Humano (UFSM); Professor Aposentado do Departamento de Metodologia do Ensino do Centro de Educação da Universidade Federal de Santa Maria (UFSM). E-mail: hnkrug@bol.com.br

${ }^{2}$ Doutora em Educaçáo em Ciências: Química da Vida e Saúde (UFSM); Professora da Universidade de Cruz Alta (UNICRUZ). E-mail: mkrug@ unicruz.edu.br

${ }^{3}$ Doutor em Ciências Médicas (UFSC); Professor da Universidade de Cruz Alta (UNICRUZ). E-mail: rodkrug@bol.com.br

${ }^{4}$ Mestre em Educação Física (UFSM); Doutorando em Educação (UFSM). E-mail: telleshz@yahoo.com.br

${ }^{5}$ Mestre em Educaçáo (UFSM); Doutorando em Educação Física (UEM). E-mail:patricflores_12@yahoo.com.br
} 


\section{Considerações iniciais}

A preocupação com a profissão docente tem sido objeto de inúmeros estudos nos últimos anos (KRUG et al., 2017a; KRUG et al., 2017b; ILHA; KRUG, 2010; CONTREIRA et al., 2009) que buscam, por diferentes caminhos, ressignificar o trabalho do professor com vistas a proporcionar uma atuação de qualidade frente aos desafios postos à escola na contemporaneidade. Segundo Alves-Mazzotti (2007, p. 580),

[...] os desafios não são poucos. $\mathrm{O}$ mundo contemporâneo vem marcado por rápidas e profundas transformaçōes decorrentes do processo de globalização, exigindo que o sujeito seja capaz de lidar com a crescente integração das economias nacionais e as novas exigências de qualificação do trabalhador [...].

Assim, exige-se que o professor acompanhe a evolução dos tempos, pois, da escola e, por conseguinte, do docente, espera-se o desempenho de novas funçôes, novos papéis.

Neste sentido, gestar uma nova escola, um novo profissional docente, capaz de lidar com as demandas da realidade contemporânea, é um desafio imenso, sendo que, para a efetivação real das mudanças desejadas, implica saber em que medida estas se aproximam das representaçóes do professor de si mesmo e da sua profissão hoje.

Desta forma, concordamos com Perrenoud (1999) quando diz que a realidade educativa não se transforma apenas pela adoção de boas ideias, mas sim pela mudança das representaçóes, atitudes, valores e da própria identidade dos atores.

Desta maneira, o conhecimento das Representaçóes Sociais (RS) do professor, como um conjunto organizado de julgamentos, atitudes e informaçôes elaborados a respeito de um objeto social com o objetivo de orientar e justificar práticas assume relevância para orientar uma atuação profissional qualificada do docente na escola. Assim, a utilização da Teoria das Representaçôes Sociais (TRS) visa aprender o senso comum de um determinado fenômeno social para compreender como um grupo de indivíduos, neste caso de professores, constrói uma compreensão do fenômeno educativo.

Para Magalhães Júnior e Tomanik (2013) as RS nascem nas relaçóes que criamos com grupos em comum, como a família e a escola, tendo parte o senso comum e o científico. Essas representaçôes também pertencem a significados não apenas vinculados à relação pensamento e linguagem, mas, por um conjunto de concepçôes que os sujeitos podem ter sobre as realidades do universo cultural. O homem é entendido como um ser social, que participa de diversas ideias sobre inúmeros assuntos, que sejam do seu interesse e curiosidade. Nessa relaçáo de opiniôes, cada indivíduo defende seu próprio conceito, formado por uma coleta de informaçóes com valores de experiências pessoais e grupais. Entretanto, Moscovici (1978) enfatiza que as RS não são apenas 'opiniōes sobre', são teorias coletivas sobre o real, baseados em valores que determinarão as ideias.

Diante deste cenário, voltamos nossos olhares para um determinado grupo de indivíduos e suas RS, ou seja, para os professores de Educação Física (EF) da Educação Básica (EB).

Portanto, a partir destas premissas supracitadas originou-se a seguinte questão problemática da investigação: quais são as RS de si mesmo e da profissão docente e suas justificativas de professores de EF da EB de 
uma cidade da regiáo central do Estado do Rio Grande do Sul-RS (Brasil)? Assim, o objetivo geral foi analisar as RS de si mesmo e da profissão docente e suas justificativas de professores de EF da EB de uma cidade da região central do Estado do RS (Brasil).

Para facilitar o atingimento do objetivo geral esse foi divido em objetivos específicos: 1) analisar as RS da profissão docente e suas justificativas de professores de EF da EB de uma cidade da região central do Estado do RS; 2) analisar as RS do trabalho docente e suas justificativas de professores de EF da EB de uma cidade da região central do Estado do RS; e, 3) analisar as RS do ser professor e suas justificativas de professores de EF da EB de uma cidade da região central do Estado do RS.

Justificamos a realização desta investigação destacando que estudos desta natureza podem oferecer subsídios para uma melhor compreensão do fenômeno do significado [representaçóes] da profissão docente em $\mathrm{EF}$ e, assim, consequentemente, auxiliar na melhoria da qualidade da atuação deste profissional.

\section{Fundamentação teórica}

Segundo Machado e Castro (2016, p. 364) a TRS “[...] foi originalmente elaborada pelos estudos de Serge Moscovici, em meados da década de 1960, e abrange uma compreensão e explicação aprofundada dos fenômenos sociais [...]". Estas autoras destacam que a "TRS foi se consolidando ao longo do tempo e dela surgiram três correntes complementares" (p.364): a) uma fiel a teoria descrita por Denise Jodelet; b) outra que enfatiza uma visão mais sociológica descrita por Willem Doise; e, c) uma outra que preconiza a dimensão cognitivo-estrutural descrita por Jean-Claude Abric.

Para Jodelet (2001, p. 22) a RS é "[...] uma forma de conhecimento, socialmente elaborada e partilhada, com um objetivo prático, e que contribui para a construçấo de uma realidade comum a um conjunto social”.

Conforme Moscovici (1978, p. 20) toda representação é a representação de algo ou de alguém sendo ela mesma composta por figuras e expressóes socializadas, "um modelo que assimilado, ensinado e comunicado dá forma a realidade".

De acordo com Moscovici (1979, p. 63) "representar um objeto é, ao mesmo tempo, conferir-lhe o status de um signo, é conhecê-lo, tornando-o significante". Toda representação é constituída em torno de um objeto, não há representação sem objeto. Entretanto, a representação difere do objeto, pois ao representá-lo o sujeito vai reconstruí-lo, ressignificá-lo, como consequência do poder criador da atividade representativa. Ao representar sujeito e objeto se misturam.

Entretanto, Moscovici (1978) enfatiza que as RS não são apenas 'opiniōes sobre', são teorias coletivas sobre o real, baseados em valores que determinarão as ideias compartilhadas pelos grupos. Assim, todas as formas de RS influenciam na formação de um indivíduo, podendo modificar suas ideias.

Já Basílio e Machado (2013) relembram que são dois os processos responsáveis pela criação das RS: a) a objetivação, que constitui-se como materialização das abstraçóes, isto é, objetivação quer dizer materializar as abstraçóes, corporificar os pensamentos, tornar físico o invisível, o impalpável, enfim, transformar em objeto, o que é representado; e, b) a ancoragem, que tem a função de incorporar o novo, o estranho às representaçóes, orientar comportamentos e interpretar a realidade. Assim, esse processo significa o enraizamento 
social da representação à interação cognitiva do objeto representado no sistema de pensamento preexistente e às transformaçôes que, em conseqüência, ocorrem num e noutro. A ancoragem não é a construçâo formal do conhecimento, mas a integração de elementos em um pensamento já construído.

Relativamente às RS das profissóes, segundo Bessa (2009), estas podem estar intimamente ligadas aos ofícios ou profissôes que os sujeitos praticam e refletem as imagens de que são detentores.

Para Borges (2007, p. 85) as representaçōes profissionais permitem edificar "[...] um saber profissional, proteger a especificidade dos grupos, orientar as condutas, antecipar as expectativas dos parceiros de acção, guiar práticas e justificar à posteriori as tomadas de posição".

Ao abordar a profissão docente Bessa (2009) destaca que a imagem que o professor constrói da sua profissão é o reflexo do seu pensamento sobre a docência relacionado com as suas percepçôes da realidade e das referências que o influenciam. Já Ribeiro et al. (2006, p.6) dizem que "[o]s professores como actores sociais constroem as suas representaçôes a partir do conjunto de ideias, opinióes, informaçóes e crenças presentes no seu contexto sociocultural".

Assim, segundo Gomes (2009, p. 13) a utilização da TRS contribui para a compreensão dos fatos educativos e se apresenta "como espaço privilegiado para vermos como as representaçôes sociais são construídas, evoluem e se transformam”.

\section{Procedimentos metodológicos}

Caracterizamos este estudo como uma pesquisa qualitativa descritiva do tipo estudo de caso. Para Trivińos (1987) a pesquisa qualitativa pretende compreender uma realidade complexa, seus desejos, crenças e interesses, isto é, os acontecimentos que nela se sucedem, os quais precisam ser compreendidos como parte do todo. Ainda para o autor, a pesquisa qualitativa descritiva tem por objetivo traduzir e expressar o sentido dos fenômenos do mundo social. Já Ponte (2006) diz que o estudo de caso é uma investigação sobre uma situação específica, procurando descobrir o que há nela de mais essencial e característico e, desse modo, contribuir para a compreensão global de certo fenômeno de interesse.

Assim, neste estudo, o caso investigado referiu-se aos professores de EF da EB de uma cidade da regiáo central do Estado do RS (Brasil). Nesse sentido, a justificativa da escolha da forma de pesquisa qualitativa, descritiva e estudo de caso foi devido à possibilidade de se analisar um ambiente em particular, onde se levou em conta o contexto social e sua complexidade para compreender e retratar uma realidade em particular e um fenômeno em especial, 'as RS de professores de EF da EB sobre si mesmos e da profissão docente'.

O instrumento utilizado para coletar as informaçôes foi um Teste de Associação Livre de Palavras que, conforme Abric (1998) procura acessar de maneira menos elaborada os elementos mais salientes de uma RS. Para Machado e Gomes (2015, p.86) a Associação Livre de Palavras "é uma técnica projetiva que procura acessar conteúdos mais espontâneos acerca de um objeto, fato ou evento, geralmente, mascarados nas produçôes discursivas". No caso desse estudo, a associação livre consistiu em solicitar aos participantes que registrassem em formulário próprio, de forma livre e imediata, a primeira palavra que lhes viessem à lembrança mediante apresentação dos seguintes estímulos indutores: 1) a profissão docente em EF é...?; 2) o trabalho 
docente em EF é...?; e, 3) o ser professor de EF é...? E, logo após a justificativa da palavra escolhida. Para a análise das informaçôes coletadas, utilizamos a análise de conteúdo de Bardin (2010).

Participaram do estudo vinte (20) professores de EF da EB de uma cidade da região central do Estado do RS (Brasil). A escolha dos participantes aconteceu de forma intencional, em que a disponibilidade dos professores foi o fator determinante para que fossem considerados colaboradores. Quanto aos aspectos éticos vinculados às pesquisas científicas, destacamos que todos os participantes assinaram o Termo de Consentimento Livre e Esclarecido e suas identidades foram preservadas.

\section{Resultados e discussões}

Os resultados e as discussões deste estudo foram explicitados e orientados pelos objetivos específicos.

\section{As representações da 'profissão docente' advindas dos professores de EF da EB estudados}

Identificamos e analisamos as 'palavras' evocadas pelos professores de EF da EB estudados mediante a apresentação do estímulo indutor: a profissão docente em EF é...? E, logo após a justificativa da palavra escolhida.

As palavras representativas da profissão docente e suas justificativas foram as seguintes:

- 'Trabalho' (doze citaçôes) - Luft (2000) coloca que trabalho significa emprego, o ofício ou a profissão de alguém. É o conjunto das atividades realizadas por alguém para alcançar um determinado fim ou propósito. São os mecanismos mentais ou intelectuais utilizados na realização de algo. A esse respeito mencionamos Basso (1998) que afirma que, no caso dos professores, o significado do trabalho é formado pela finalidade da ação de ensinar, ou seja, pela ação concretizada e consciente do docente. Na única justificativa existente, a palavra 'trabalho' foi usada com o indicativo de 'indispensável (doze citaçóes). Convém lembrarmos que, segundo Luft (2000), indispensável é aquilo que não se pode dispensar, é imprescindível. Assim, de acordo com Ferreira; Teotônio e Barbosa (2017, p.s.n.) "[o] trabalho é a atividade indispensável para reprodução social de toda e qualquer sociedade e refere-se à relação do homem com a natureza, procedendo de forma que o homem ao transformá-la em uma base material necessária para atender suas necessidades humanas". Ao realizar-se essa transformação, o trabalho desencadeia e desenvolve novas necessidades bem como eleva a capacidade produtiva não somente individual, mas abre também novas possibilidades de desenvolvimento social (LESSA, 2007); e,

- 'Sustento' (oito citaçôes) - Conforme Luft (2000) sustento significa o ato ou efeito de sustentar. É o alimento, amparo, arrimo, esteio. Nesse sentido, nos referimos a Contreira et al. (2009) que destacam que perceber e se contentar com um salário baixo é uma das implicaçôes da decisão de ser professor de EF para a vida pessoal e profissional. Na única justificativa existente, a palavra 'sustento' apareceu associada ao indicativo de 'desafio' (oito citaçóes). Luft (2000) coloca que desafio é a ação ou efeito de desafiar. Desafiar é provocar. Nesse sentido, podemos inferir que o sustento pessoal e familiar pelo professor é um desafio na sociedade atual. Na perspectiva desse cenário citamos Ramos e Spgolon (2005) que fazem o seguinte questionamento: como o professor com um salário baixo irá proporcionar ao seu aluno um 
ensino atualizado, diversificado e de qualidade, se com o salário que ganha, mal consegue sobreviver? Salientam que alguns têm vontade de fazer cursos de especialização, de pós-graduação, enfim progredir profissionalmente, mas não possuem condiçóes financeiras. Isto de certa forma faz com que o professor se sinta minimizado em relação às demais profissões.

Assim, estas foram as palavras representativas da profissão docente e suas justificativas apontadas pelos professores de EF da EB estudados. E, nesse sentido, podemos destacar que estas palavras estão em consonância com o salientado por Bessa (2009) que diz que as RS sobre determinada profissão relacionam-se com o tipo de trabalho que o indivíduo executa.

\section{As representações do 'trabalho docente' advindas dos professores de EF da EB estudados}

Identificamos e analisamos as 'palavras' evocadas pelos professores de EF da EB estudados mediante a apresentação do estímulo indutor: o trabalho docente em EF é...? E, logo após a justificativa da palavra escolhida.

As palavras representativas do trabalho docente e suas justificativas foram as seguintes:

- 'Ensinar' (nove citações) - Para Luft (2000) ensinar significa instruir sobre; lecionar. Oferecer condições para que alguém aprenda. Já Tardif (2005, p.31) coloca que: “[...] ensinar é trabalhar com seres humanos, sobre seres humanos, para seres humanos. Esta impregnação do trabalho pelo 'objeto humano' merece ser problematizada por estar no centro do trabalho docente". Na única justificativa existente, a palavra 'ensinar' apareceu com a conotação específica de que 'é a tarefa do professor' (nove citaçóes), fato esse reafirmado por Nóvoa (1995) que diz que a tarefa básica do professor é ensinar. Já Volpato et al. (2011) afirmam que o ensino historicamente está atrelado à atividade docente. Ensinar é tarefa do professor, apesar de não ser unicamente, e está relacionado sempre com a formação dos sujeitos;

- 'Gratificante' (cinco citações) - De acordo com Luft (2000) gratificante significa uma característica do que gratifica, que é capaz de causar certa satisfação ou acarreta algum tipo de contentamento interior. Nesse sentido, Noal (2003) destaca que a sensação de gratificação do professor pode ser conseguida com a segurança e a confiança que este possui ao desempenhar a sua função entre outros aspectos que influenciam na saudável relação entre professor-aluno e consequentemente resultar em sucesso profissional. $\mathrm{Na}$ única justificativa existente, a palavra 'gratificante' foi usada com o indicativo de 'prazer' (cinco citaçóes). Luft (2000) diz que prazer significa alegria, contentamento, júbilo, deleite, gosto, satisfação, sensação agradável, distração, divertimento. Emoção agradável que resulta da atividade satisfeita. Nesse direcionamento de ideia citamos Silva e Krug (2004) que dizem que o professor precisa se sentir, antes de mais nada, como uma pessoa que faz parte da sociedade, que pode ter alguma limitaçáo, como qualquer outra pessoa e/ou profissional, mas que também possui potencial e capacidade para desenvolver atividades que propiciem prazer e satisfação para ter uma sensação de gratificação com aquilo que faz;

- 'Desvalorização' (três citaçôes) - Para Luft (2000) desvalorização significa perda de valor, depreciação, baixa do valor da moeda de um país em relação ao ouro. Nesse sentido, é fundamental mencionarmos Castilho; Charão e Ligabue (2004) que afirmam que a desvalorização do magistério é um processo 
antigo, pois com o passar do tempo esta categoria foi tendo uma mutaçáo, ou seja, aconteceu uma defasagem salarial, uma desvalorização profissional, e quem mais sofre são os profissionais da rede pública de ensino. Para Basílio e Machado (2013) a palavra desvalorização revela certa indignação para com o desprestígio social e aparente desvalor da profissão e do curso de licenciatura. $\mathrm{Na}$ única justificativa existente, a palavra 'desvalorizaçấo' apareceu sob a influência dos 'baixos salários e condiçóes precárias de trabalho' (três citaçóes) dos docentes, fato esse constatado no estudo de Krug (2008) intitulado "Vale a pena ser professor... de Educação Física Escolar?” E, nesse direcionamento de constatação ainda citamos Gatti (2000) que destaca que ser professor do ensino básico tem se mostrado cada vez menos atraente, tanto pelas condiçôes de formaçấo oferecidas pelos cursos em si, quanto pelas condiçôes em que seu exercício se dá e pelas condiçóes salariais;

- 'Estressante' (duas citações) - Conforme Luft (2000) estressante é aquilo que causa estresse. Estresse é a exaustão física ou emocional provocada por várias e distintas razões, por sofrimento, doença, cansaço, pressão, trauma, sendo definida pela perturbação da homeostasia, do equilíbrio, que leva o organismo a se adaptar através do aumento da secreçâo da adrenalina. Nesse contexto, lembramos Patto (1983) que diz que o professor está inserido em um sistema complexo de relaçóes humanas e por isso é passível de influência de fatores considerados estressantes. Nesse sentido, segundo Ilha e Krug (2010), sendo o sistema de relaçóes humanas nas aulas de EF muito complexo, porque os alunos estão em movimento, é lógico que estes professores tendem a possuir um nível de stress ocupacional muito elevado. Nas justificativas, a palavra 'estressante' foi sempre abordada relacionada 'as diversas tarefas e funçôes dos docentes' (duas citaçôes) e, dessa forma, citamos Villas Boas et al. (1988) que afirmam que há stress relacionado às tarefas e às funções do professor; $\mathrm{e}$,

- 'Isolado' (uma citação) - De acordo com Luft (2000) isolado significa só, solitário, separado dos outros homens. Nesse sentido, mencionamos Marcondes (1997) que afirma que nas escolas ainda encontramos professores que desenvolvem suas atividades de modo isolado, isto é, professores da mesma escola, trabalhando no mesmo turno e da mesma série, que mantém pouco, ou nenhum, contato entre si. Não discutem o próprio trabalho que desenvolvem, não planejam suas atividades sobre o programa estabelecido no início do ano, não colocam as suas dúvidas, incertezas, problemas comuns. Demonstram que encaram a tarefa de ensinar de forma extremamente isolada. Já Alarcão (2003) diz que o professor não pode agir isoladamente na sua escola, pois é neste local, o seu local de trabalho, que ele, com os outros, seus colegas, constrói a profissionalidade docente. $\mathrm{Na}$ justificativa, a palavra 'isolado' foi usada tendo estreita relação com o 'individualismo' (uma citação) e, nesse direcionamento de sentido nos reportamos a Luft (2000) que diz que individualismo significa a tendência a não pensar senão em si. Tendência a libertar-se de toda solidariedade com seu grupo social, a desenvolver excessivamente o valor e o direito do indivíduo. Nesse sentido, Würdig (1999) destaca que a estrutura e a rotina das escolas, parecem provocar o individualismo dos professores, pois não são privilegiados momentos de trocas de experiências, de organização, de planejamento e projetos coletivos, de diálogo e relatos sobre a prática pedagógica, no sentido de ampliar a formação continuada. Já Krug (1996b) salienta que não se chega a um bom resultado no ensino da EF com os professores numa posição de individualismo e de isolamento profissional. 
Assim, estas foram as palavras representativas do trabalho docente e suas justificativas apontadas pelos professores de EF da EB estudados. E, nesse sentido, estas palavras estão em consonância com o colocado por Bessa (2009, p.25) que diz que "[o] professor é um sujeito que edifica sentidos sobre a realidade em que actua. Assim, desenvolve um processo de análise, compreensão e construção da realidade que condiciona a sua forma de estar e ser".

\section{As representações do 'ser professor' advindas dos professores de EF da EB estudados}

Identificamos e analisamos as 'palavras' evocadas pelos professores de EF da EB estudados mediante a apresentaçáo do estímulo indutor: o ser professor de EF é...? E, logo após a justificativa da palavra escolhida.

As palavras representativas do ser professor e suas justificativas foram as seguintes:

'Educador' (seis citaçôes) - Segundo Luft (2000) educador significa aquele que educa ou que se ocupa de educação. Pedagogo, professor. Conforme Carneiro (2007) o conceito de educador pode ser visto como uma característica intrínseca ao professor e à sua profissão. Já Behrens (2003) afirma que é indispensável que o professor tenha consciência de que seu papel é ser educador. Seu papel envolve não somente o conhecimento técnico e específico da área, como também o de ser professor, aliado ainda à formação de seres humanos, com valores, atitudes, ética e postura profissional. Para Luckesi (1992) o professor educador é aquele que tendo adquirido o nível de cultura necessária para o desempenho de sua função, dá direção ao ensino e à aprendizagem. Ele assume o papel de mediador entre a cultura elaborada, acumulada e em processo de acumulação pela humanidade e o educando. O professor deverá fazer a mediação entre os resultados da cultura, ou seja, o coletivo da sociedade e o individual do aluno. O seu papel é o de mediador social entre o universo da sociedade e o particular do educando. Para que possa exercer sua função, o professor deve possuir conhecimentos e habilidades suficientes para poder auxiliar o aluno no processo de elaboração cultural. Nas justificativas, a palavra 'educador' foi sempre abordada relacionada à 'educação' (seis citaçóes) e, nesse sentido, citamos Mizukami (1986) que diz que existem várias formas de se conceber a educação, pois esta, pela sua própria natureza, não é uma realidade acabada que se dá a conhecer de uma forma única e precisa em seus múltiplos aspectos. A educação é um fenômeno humano, histórico e multidimensional. Nele está presente, tanto a dimensão humana quanto a técnica, a cognitiva, a emocional, a sóciopolítico e cultural. Não se trata de uma justaposição das referidas dimensões, mas, sim, de aceitação de suas múltiplas implicações e relações. Destaca que as diferentes formas de aproximação da educação podem ser consideradas como mediaçóes historicamente possíveis, que permitem explicá-lo, se não em sua totalidade, pelo menos em alguns de seus aspectos; por isto, devem ser analisadas, contextualizadas e discutidas criticamente. Assim, de acordo com determinada teoria/proposta ou abordagem do processo ensino-aprendizagem, privilegia-se um ou outro aspecto da educação. A autora esclarece que o que denomina de 'abordagem' são diferentes linhas pedagógicas ou tendências ou concepçóes no ensino brasileiro;

'Vocação' (cinco citaçôes) - Conforme Luft (2000) vocação significa inclinação que se sente para alguma coisa. Disposição natural do espírito. Inclinação para a vida religiosa. Nesse sentido, Gauthier et al. (1998) destacam que um dos obstáculos do trabalho docente são as representaçôes, que se interpóem na percepção 
de uma ciência da educação, onde desconsidera as condiçôes concretas em que se desenvolve a docência e a produção de saberes profissionais, produzindo uma espécie de cegueira conceitual, mostrando a profissão docente como um 'ofício sem saberes'. As representaçôes que levam a esta situação são as seguintes: a) basta conhecer o conteúdo; b) basta ter talento; c) basta ter bom senso; d) basta seguir a intuição; e) basta ter experiência; e, f) basta ter cultura. Nas justificativas, a palavra 'vocaçâa' foi utilizada com a conotação de um 'dom da pessoa' (cinco citaçôes). A esse respeito citamos Assumpção (1996) que afirma que a 'vocação' encontra-se associada a algo pertencente à ordem do místico, relacionada à 'dom', à qualidades especiais à 'missão' de ensinar, a doação, enfim o magistério como sacerdócio. Existe, sem dúvida, no discurso da 'vocação' a marca provocada pelos mais diversos entrelaçamentos, entre eles, a estreita relação, historicamente construída, entre religião e educação. Relação essa que contribuiu não só para a representação como um sacerdócio, mas também para o perfeito casamento entre mulher e magistério. Também Perrenoud (1997) salienta que alguns professores possuem uma concepção ultrapassada da profissão, acreditando que o saber-fazer pedagógico é uma questão de dom ou de experiência o que leva a pensar que não tem nada a aprender com outros especialistas;

'Profissional (quatro citaçóes) - Para Luft (2000) profissional significa que se relaciona com determinada profissão. Ou ainda, é não amador, cuja atividade é exercida como profissão, trabalho. Relativamente a isso mencionamos Moraes (1996) que diz que a profissionalização do professor ocorre essencialmente na prática e é por meio de sua prática que o professor constrói suas crenças e pressupostos e estes o conduzem a construir seu próprio projeto de educação. Ressalta que esse processo pode ser concebido como um movimento de auto-educação que torna o professor um profissional cada vez mais autônomo e competente. Já Krug e Krug (2008) destacam que ser profissional é uma das características pessoais do bom professor de EF. $\mathrm{Na}$ única justificativa existente, a palavra 'profissional foi usada com a conotação de 'assumir responsabilidades na formação dos alunos' (quatro citações). Nesse sentido, mencionamos Bolzan (2002) que coloca que a tomada de consciência do papel do professor, entendida aqui, como elemento dinamizador do processo de escolarização e, portanto, organizador da intervenção pedagógica a ser implementada, é fundamental, considerando a importância da redimensão das práticas escolares vigentes. Já Contreira et al. (2009) destacam que assumir responsabilidades na formação do aluno é uma das implicações da decisão de ser professor de EF para a vida pessoal e profissional;

'Conhecimento' (três citaçôes) - Segundo Luft (2000) conhecimento significa ato ou efeito de conhecer. Faculdade de conhecer. Ideia, noção, informação, notícia. Saber, instrução, perícia. Nesse sentido, Cunha (1992) coloca que o professor tem que ter um profundo conhecimento do que se propóe a ensinar. Isto não significa uma postura prepotente que pressuponha uma forma estanque de conhecer. Ao contrário, o professor que tem profundo domínio do conteúdo é aquele que trabalha com a dúvida, que analisa a estrutura de sua matéria de ensino e é profundamente estudioso naquilo que lhe diz respeito. Já Matos (1994) destaca que, entre outros conhecimentos, o professor para ter um trabalho docente eficiente deve ter conhecimento do conteúdo da disciplina. Para Krug (1996a) é de fundamental importância o professor ter conhecimentos objetivos a respeito de tudo o que for relevante ao processo pedagógico, pois toda açấo consciente depende da existência de conhecimentos. Nas justificativas, a palavra 'conhecimento' foi usada com o indicativo de 'competência profis- 
sional (três citaçôes) e, dessa forma, Krug (1996a) coloca que não há competência sem conhecimentos, sendo que, nesse sentido, que os conhecimentos são frequentemente designados como os componentes fundamentais da competência. Sem conhecimentos, não é possível formar capacidades, nem habilidades para a atividade pedagógica, que terão de serem sempre trabalhadas em referência aos conhecimentos; e,

'Amigo' (duas citaçóes) - De acordo com Luft (2000) amigo significa um indivíduo com quem se tem uma relação de amizade, de afeto, de companheirismo. Nesse sentido, Cordeiro e Haddad (2009) afirmam que a imagem do professor amigo sugere a existência de uma faceta com forte significação afetiva. Já segundo Bessa (2009) esta imagem de amigo revela a vertente humana e relacional do professor que exerce a sua profissão num mundo de interaçôes relacionais com pares, alunos e pais refletindo-se na sua concepção de professor e na sua representaçấo. Entretanto, Pardal et al. (2009) destacam que a imagem de professor associada à afetos e a amizade revela os traços mais conservadores nomeadamente no caráter relacional resultante das interaçôes. Nas justificativas, a palavra 'amigo' foi sempre abordada no sentido de 'se relacionar bem com os alunos' (duas citaçôes) e, nesse direcionamento de sentido, citamos Darido e Rangel (2005) que destacam que o sucesso e o insucesso do processo ensino-aprendizagem depende da interação professor-aluno na aula. Assim a boa relação está ligada ao sucesso e a má relação ao insucesso.

Assim, estas foram as palavras representativas do ser professor e suas justificativas apontadas pelos professores de EF da EB estudados. E, nesse sentido, podemos destacar que estas palavras estáo em consonância com o afirmado por Cosme (2009) de que o professor é um ser formado por crenças e representaçôes diversas e por um conjunto de saberes que determinam a sua imagem pública e privada. Esta imagem deverá constituir uma referência sólida no processo de definição do que é ser professor.

\section{Considerações finais}

Pela análise das informaçóes obtidas dos professores de EF da EB estudados foi possível representar a profissão docente em duas palavras (trabalho e sustento), o trabalho docente em cinco palavras (ensinar, gratificante, desvalorizaçâo, estressante e isolado) e ser professor também em cinco palavras (educador, vocação, profissional, conhecimento e amigo).

Destacamos que estas palavras representativas da profissão docente, do trabalho docente e do ser professor podem ter surgido de convicções pessoais, projeçóes futuras de atuação profissional, de influências de grupos, pessoas e ou instituiçôes de todas as naturezas das quais os sujeitos tenham interagido em suas vidas. E esse destaque está em consonância com o dito por Abric (1994) de que as RS articulam várias funçôes nos grupos sociais, não se limitando à função do saber, mas também identitária, avaliativa e reguladora das práticas sociais.

Entretanto, o que chamou à atenção no rol de palavras representativas da profissão docente, do trabalho docente e do ser professor manifestado pelos professores estudados foi que 'apresentou palavras com conotaçôes positivas e negativas'.

De acordo com Luft (2000) positivo é algo que tende a auxiliar para a melhoria de alguma coisa. 
Assim, para esta investigação, consideramos positiva, a representação (palavra) apontada pelos professores estudados que tendeu para auxiliar em uma boa imagem da profissão docente, do trabalho docente e do ser professor. Também Luft (2000) diz que negativo é algo que contém ou exprime recusa, é contraproducente. Assim, para esta investigação, consideramos negativa, a representação (palavra) apontada pelos professores estudados, que tendeu para tornar contraproducente a imagem da profissão docente, do trabalho docente e do ser professor.

As palavras com conotações positivas foram: trabalho; sustento; ensinar; gratificante; educador; vocação; profissional; conhecimento; e, amigo. As com conotaçóes negativas foram: desvalorizaçāo; estressante; e, isolado. Assim, constatamos que a profissão docente (duas) e o ser professor (cinco) foram totalmente representados por palavras positivas, mas no trabalho docente aconteceu uma polarização entre palavras negativas (maioria $=$ três) e positivas (minoria=duas).

Entretanto, podemos destacar que na totalidade das palavras representativas da profissão docente, do trabalho docente e do ser professor foi maior o número de palavras com conotaçóes positivas (nove palavras) do que as com conotações negativas (três palavras). Já quanto ao número de citações de palavras com conotaçóes positivas (cinquoenta e quatro no total) foram em número muito superior as palavras com conotaçóes negativas (seis no total).

Também podemos constatar que os resultados sinalizam no direcionamento de elementos de uma RS da profissão docente e do ser professor pelos professores estudados marcada totalitariamente por palavras associadas à conotaçóes positivas, mas também, no direcionamento de elementos de uma RS do trabalho docente marcado majoritariamente, por palavras associadas à conotaçóes negativas. Todavia, ao olharmos para o número de citações das palavras que compuseram a representação da profissão docente, do trabalho docente e do ser professor como um todo, verificamos que a RS foi majoritariamente marcada por palavras associadas à conotações positivas.

Assim, os resultados apontaram que o conteúdo geral das RS da profissão docente, do trabalho docente e do ser professor dos professores estudados apareceu como uma amálgama em que vários elementos se interpenetram. Trata-se de um conteúdo que agrega o próprio indivíduo e a profissão docente. Os professores estudados não separaram as duas coisas.

Convém lembrar que, segundo Moscovici (2010), as RS são estruturas dinâmicas e complexas, fruto de um conjunto de relaçôes e comportamentos que surgem e desaparecem. Eles se ancoram em sistemas de crenças, valores, tradiçôes e imagens do mundo a partir de um pensamento preexistente, tornando possível a mobilização de elementos novos que se juntam aos já existentes, somando-as ou transformando-as.

Desta forma, podemos concluir que os resultados deste estudo evidenciaram que as RS dos professores de EF da EB estudados são em sua maioria representadas por palavras como conotaçóes positivas o que infere que a profissão docente, o trabalho docente e o ser professor são bem vistos pelos pesquisados.

Neste sentido, concluímos que o habitus constituído pelos sujeitos em suas trajetórias sociais é um elemento norteador de suas compreensóes de mundo, das pessoas e suas açóes, podendo assim, facilitar ou dificultar as suas representaçóes da profissão docente, do trabalho docente e do ser professor. Para Catani (2002) o conceito de habitus se refere às predisposiçôes duráveis do modo de agir, pensar e viver e se portar 
dos indivíduos. Segundo Nogueira e Nogueira (2002, p.19) o habitus é adquirido pelo convívio social, assim, "os gostos mais íntimos, as preferências, as aptidões, as posturas corporais, a entonação da voz, as aspiraçôes relativas ao futuro profissional, tudo seria socialmente constituído".

Para finalizar, reconhecemos a necessidade de estudos mais aprofundados que este, já que, de acordo com o alerta de Sá (1998), os fenômenos representacionais não podem ser captados pelas pesquisas de modo completo e direto, pois são, por natureza, difusos, fugidios, multifacetados, em constante movimento e presentes em inúmeras instâncias da interação social.

\section{Referências}

ABRIC, J.C. Prácticas sociales y representaciones. México: Ediciones Coyoacán, 1994.

. A abordagem estrutural das representações sociais. In: MOREIRA, A.S.P.; OLIVEIRA, D.C. de.

(orgs.) Estudos interdisciplinares de representação social. Goiânia: Ed. AB, 1998.

ALARCÃO, I. Professores reflexivos em uma escola reflexiva. São Paulo: Cortez, 2003.

ALVES-MAZZOTTI, A.J. Representaçóes da identidade docente: uma contribuição para a formulação de políticas. Revista Ensaio: Avaliação, Políticas Públicas e Educação, Rio de Janeiro, v. 15, n. 57, p. 579594, out./dez., 2007.

ASSUMPÇÃO, M.M.S. Magistério primário e cotidiano escolar. Campinas: Autores Associados, 1996.

BARDIN, L. Análise de conteúdo. Lisboa: Ediçóes 70, 2010.

BASÍLIO, M.A.T.; MACHADO, L.D. O curso de Pedagogia: nas representaçóes sociais de estudantes em formação. Revista Profissáo Docente Online, Uberaba, v. 13, n. 28, p.99-119, jan./jun., 2013.

BASSO, I.S. Significado e sentido do trabalho docente. Revista Caderno CEDES, Campinas, v. 19, n. 44, p. 19-32, 1998.

BEHRENS, M.A. A formação pedagógica e os desafios do mundo moderno. In: MASETTO, M. (org.). Docência na universidade. Campinas: Papirus, 2003.

BESSA, A.M.F. dos S. Professor do ensino básico: representação social de si e da profissão. 2009. Dissertação (Mestrado em Ciências da Educação) - Universidade de Aveiro, Aveiro, 2009.

BOLZAN, D.P.V. Formaçáo de professores: compartilhando e reconstruindo conhecimento. Porto Alegre: Mediação, 2002.

BORGES, M.P. da A. Professores: imagens e auto-imagens, 2007. Tese (Doutorado em Ciências da Educação) - Universidade Técnica de Lisboa, Lisboa, 2007.

CARNEIRO, M.H. da S. Prática pedagógica no ensino fundamental: um estudo das representaçóes sociais de alunos do curso de Pedagogia. In: PARDAL, L. et al. (orgs.). Educaçáo e trabalho: representaçôes, competências e trajectórias. Aveiro: Universidade de Aveiro, 2007. 
CASTILHO, A.L.; CHARÃO, C.; LIGABUE, L. Quanto vale um professor? Revista Educação, São Paulo: Segmento, jun., 2004.

CATANI, A.M. A Sociologia de Pierre Bourdieu (ou como um autor se torna indispensável ao nosso regime de leituras). Revista Educaçáo \& Sociedade, São Paulo, n. 78, p. 57-75, abr., 2002.

CONTREIRA, C. et al. As implicações da decisão de ser professor de Educação Física para a vida pessoal e profissional: a compreensão dos acadêmicos da licenciatura do CEFD/UFSM. Boletim Brasileiro de Educação Física, Brasília, p.1-7, set., 2009.

CORDEIRO, M.H.B.; HADDAD, L. Delineando modelos de escola e perfil de professor: um estudo com estudantes do Vale do Itajaí e da Universidade Federal de Alagoas. In: SOUSA, C.P. de et al. (orgs.). Representaçóes sociais sobre o trabalho docente. Aveiro: Universidade de Aveiro, 2009.

COSME, A. Ser professor: a acção docente como uma acção de interlocução qualificada. Porto: Livpsic, 2009.

CUNHA, M.I. O bom professor e sua prática. Campinas: Papirus, 1992.

DARIDO, S.C.; RANGEL, I.C.A. (Coords.). Educaçáo Física na escola: implicações para a prática pedagógica. Rio de Janeiro: Guanabara Koogan, 2005.

FERREIRA, A.L.M.; TEOTONIO, L. de B.C.; BARBOSA, S.K.C. As determinaçóes do trabalho no modo de produçáo capitalista, 2017. Disponível em: <http://www.memoriaoperaria.org.br/as-determinacoes>. Acesso em: 06 jul. 2017.

GATTI, B.A. Formaçáo de professores e carreira: problemas e movimentos de renovação. Campinas: Autores Associados, 2000.

GAUTHIER, C. et al. Por uma teoria da Pedagogia: pesquisas contemporâneas sobre o saber docente. Ijuí: Ed. UNIJUÍ, 1998.

GOMES, A.A. Apresentação Dossiê: representaçóes sociais e educação. Revista Nuances: Estudos Sobre Educaçáo, Presidente Prudente, v. 16, n. 17, p. 21-33, jan./dez., 2009.

ILHA, F.R. da S.; KRUG, H.N. O professor de Educação Física Escolar e o stress na sua profissão. Revista InterMeio, Campo Grande, v.16, n.31, p.238-245, jan./jun., 2010.

JODELET, D. Representaçôes sociais: um domínio em expansão. In: JODELET, D. As representações sociais. Rio de Janeiro: UERJ, 2001.

KRUG, H.N. A competência pedagógica do professor de Educação Física. In: CANFIELD, M. de S. (Org.). Isto é Educaçáo Física! Santa Maria: JtC Editor, 1996a.

A reflexão na prática pedagógica do professor de Educação Física, 1996. Dissertação (Mestrado em Ciência do Movimento Humano) - Universidade Federal de Santa Maria, Santa Maria, $1996 \mathrm{~b}$.

. Vale a pena ser professor... de Educação Física Escolar? Revista Digital Lecturas: Educa-

ción Física y Deportes, Buenos Aires, n.122, p.1-7, jul., 2008. 
KRUG, H.N. et al. O curso de Licenciatura em Educação Física nas representaçóes sociais de estudantes em formação. Revista Debates em Educaçáo, Maceió, v.9, n.17, p.129-153, jan./abr., 2017a.

KRUG, H.N. et al. A representação social do ser professor de acadêmicos da Licenciatura em Educação Física antes e depois da formação inicial. Revista Educaçáo, Ciências e Cultura, Canoas, v.22, n.1, p.8195, mar., 2017b.

KRUG, R. de R.; KRUG, H.N. As características pessoais do bom professor na opinião dos acadêmicos da licenciatura em Educação Física do CEFD/UFSM. Revista Digital Lecturas: Educación Física y Deportes, Buenos Aires, n.126, p.1-15, nov., 2008.

LESSA, S. Para compreender a ontologia de Lukács. Ijuí: Ed. UNIJUÍ, 2007.

LUCKESI, C.C. Filosofia da educaçáo. São Paulo: Cortez, 1992.

LUFT, C.P. MiniDicionário Luft. São Paulo: Ática/Scipione, 2000.

MACHADO, L.B.; CASTRO, T.R.A. de. Profissão docente: representações sociais de futuros professores. Revista Cocar, Belém, v.10, n.19, p.361-381, jan./jul., 2016.

MACHADO, L.B.; GOMES, V.C. Formação na licenciatura: representações sociais de estudantes. Revista Roteiro, Joaçaba, v.40, n.1, p.79-100, jan./jun., 2015.

MAGALHÂES JÚNIOR, C.A.O.; TOMANIK, E.A. Representaçôes sociais de meio ambiente: subsídios para a formação continuada de professores. Revista Ciências \& Educaçáa, Bauru, v.1, n.19, p.181-199, 2013.

MARCONDES, M.I. O papel pedagógico político do professor: dimensôes de uma prática reflexiva. Revista da Educaçáo ABC, n.104, p.35-44, 1997.

MATOS, Z.A. Avaliação da formação de professores. Boletim da Sociedade Portuguesa de Educaçáa Física, Lisboa, n.11, p.53-70, 1994.

MIZUKAMI, M. da G.N. Ensino: as abordagens do processo. São Paulo: EPU, 1986.

MOSCOVICI, S. A representaçáo social da psicanálise. Rio de Janeiro: Zahar, 1978.

El psicoanálisis, su imagen y su público. Buenos Aires: Huemul, 1979.

Representaçóes sociais: investigaçóes em Psicologia Social. Petrópolis: Vozes, 2010.

MORAES, R. Compreendendo a profissionalização mediante história de vida de bons professores. Educaçáo, Porto Alegre, n.31, p.103-118, 1996.

NOAL, I.K. Manifestaçóes do mal-estar docente na vida de professores do ensino fundamental: um estudo de caso, 2003. Dissertação (Mestrado em Educação) - Universidade Federal de Santa Maria, Santa Maria, 2003. 
NOGUEIRA, M.A.; NOGUEIRA, C.M. Sociologia de Pierre Bourdieu: limites a contribuiçóes. Revista Educaçáo \& Sociedade, São Paulo, n.78, p.15-35, 2002.

NÓVOA, A. Diz-me como ensinas, dir-te-ei quem és e vice e versa. In: FAZENDA, I. (Org.). A pesquisa em educaçáo e as transformaçóes do conhecimento. Campinas: Papirus, 1995.

PARDAL, L. et al. Identidade e trabalho docente: representaçóes sociais de futuros professores. In: SOUSA, C.P. de et al. (Orgs.). Representaçóes sociais sobre o trabalho docente. Aveiro: Universidade de Aveiro, 2009.

PATTO, M.H.S. Introdução à Psicologia Escolar. São Paulo: T.A. Queirós, 1983.

PERRENOUD, Ph. Práticas pedagógicas, profissão docente e formação: perspectivas sociológicas. Lisboa: Publicações Dom Quixote, 1997.

Construir competências desde a escola. Porto Alegre: Ates Médicas Sul, 1999.

PONTE, J.P. da. Estudos de casos em Educação Matemática. Revista Bolema, Rio Claro, n.25, p.105$132,2006$.

RAMOS, F.M.; SPGOLON, A. Ser educador, até quando vale a pena. In: HETGES, A. et al. (Orgs.). Construindo práticas educativas interdisciplinares. Cruz Alta: UNICRUZ, 2005.

RIBEIRO, M. et al. Representaçóes sociais de professores sobre afectividade. Revista Estudo de Psicologia, Campinas, v.23, n.1, jan./mar., 2006.

SÁ, C.P. de. A construçáo do objeto de pesquisa em representaçóes sociais. Rio de Janeiro: EdUERJ, 1998..

SILVA, M.S. da; KRUG, H.N. Os sentimentos de bem ou mal-estar docente dos professores de Educaçáo Física Escolar no ensino fundamental de Santa Maria (RS): um estudo fenomenológico. Revista Biomotriz, Cruz Alta, n.2, p.38-49, 2004.

TARDIF, M. Saberes docentes e formaçáo profissional. Petrópolis: Vozes, 2005.

TRIVIÑOS, A.N.S. Introduçáo à pesquisa em ciências sociais - pesquisa qualitativa em educação. São Paulo: Atlas, 1987.

VILLAS BOAS, A. et al. Perspectivas y problemas de la función docente. Madrid: Notigraf, 1988.

VOLPATO, G. et al. Desafios da profissão e problemas na formação de professores na percepção de acadêmicos de Artes Visuais e Matemática. Revista Educaçáo em Perspectiva, Viçosa, p.222-245, jul./ dez., 2011.

WÜRDIG, R.C. Dos bancos universitários aos pátios escolares: da formação inicial à prática pedagógica dos professores de Educação Física. In: VERONEZ, L.F.; MENDEZ, V. (Orgs.). XVIII Simpósio Nacional de Educaçáo Física. Pelotas: UFPEL, 1999. 